\title{
FEATURE Gypsum as a soil amendment to enhance water quality by reducing soluble phosphorus concentrations
}

\author{
David Kost, Joe Nester, and Warren A. Dick
}

$\mathrm{t}$ is said that lakes are born to die. As soon as a lake basin is formed, either slowly by glacial action as for the Great Lakes or rapidly by the New Madrid earthquake for Reelfoot Lake, Tennessee, in 1811 to 1812 (USGS 2012), it fills with water. It then begins to accumulate sediments and nutrients, including phosphorus $(\mathrm{P})$, that increase productivity. This ultimately results in the lake basin filling with sediments and organic materials. The Maumee River drainage basin (area of 21,050 $\mathrm{km}^{2}$ $\left.\left[8,132 \mathrm{mi}^{2}\right]\right)$ on the western edge of Lake Erie occurs primarily in Ohio but also includes parts of Indiana and Michigan (figure 1). The basin has high agricultural productivity, with approximately $80 \%$ of the land devoted to row crop corn ( $\mathrm{Zea}$ mays L.) and soybeans (Glycine max [L.] Merr.).The Maumee River drains into the shallow western basin of Lake Erie and contributes most of the sediment and onethird of soluble P that enters Lake Erie.

Runoff from agricultural fields often contains excessive $\mathrm{P}$ that impacts water bodies in a process called cultural eutrophication (National Academy of Sciences 1969). Beginning in the 1950s, Lake Erie was strongly affected by cultural eutrophication (Verduin 1969). In the 1960s there were large blooms of the cyanobacterium ("blue-green algae") Microcystis and the attached green alga Cladophora. Microcystis and other cyanobacteria produce toxins that can harm humans and other animals that contact or ingest tainted water.

Beginning in the 1960 s, strong efforts were expended to reduce $\mathrm{P}$ input to the lake. These included banning phosphates $\left(\mathrm{PO}_{4}\right)$ from detergents, upgrading the treatment of sewage and other point sources of $\mathrm{P}$, and adopting conservation tillage in agriculture to reduce erosional

David Kost is a research associate, Ohio Agricultural Research and Development Center, Ohio State University, Wooster, Ohio. Joe Nester is director of Nester Ag, Bryan, Ohio. Warren A. Dick is professor emeritus, Ohio Agricultural Research and Development Center, Ohio State University, Wooster, Ohio.

\section{Figure 1}

(a) Maumee River watershed and (b) Microcystis cyanobacteria bloom in western Lake Erie on September 20, 2016 (NOAA 2016).

(a)

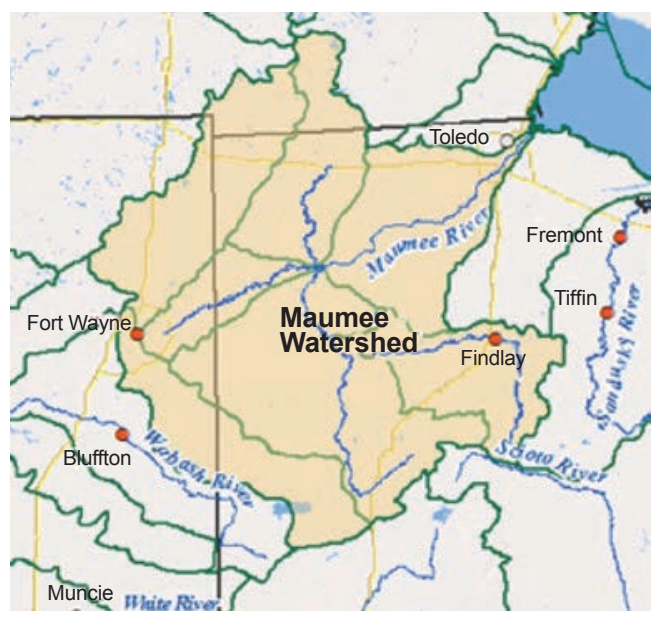

(b)

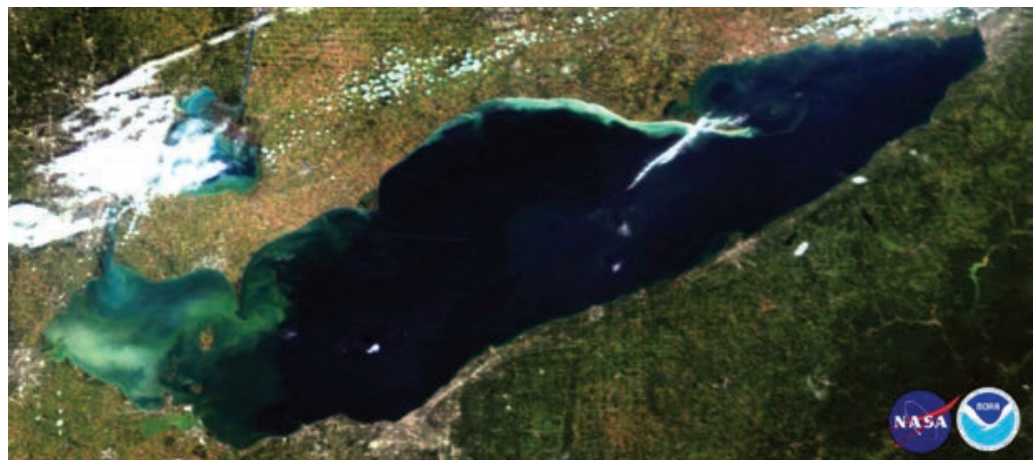

input of $\mathrm{P}$ attached to soil particles. These practices resulted in decreased blooms during the 1970s.

The return of cyanobacterial blooms to the western Lake Erie basin around 1995 implicated nonpoint sources, including agricultural runoff, as sources of $\mathrm{P}$ entering the lake. Since 1995, there has been a bloom in the western basin each year. In 2011, the city of Toledo, Ohio, spent several thousand additional dollars per day treating water affected by cyanobacterial blooms. In 2013 the entire surface of the lake was covered with algal blooms, and in August of 2014, a toxic bloom in western Lake Erie led to a two-day drinking water ban in Toledo. Although considered less severe in 2016 than in some recent years, the algal blooms caused by Microcystis cyanobacteria are still clearly evident (figure 1).
Drainage of water from fields via tile is extremely important in managing fields in the Maumee River watershed because of the cool humid climate and high water tables. Without subsurface (tile) drainage, row crop agriculture would be extremely limited. There is a clear connection between tile flow and nutrient movement from fields. Smith et al. (2015) have reported that treating only surface water runoff would not achieve the goal of $41 \%$ reduction in $\mathrm{P}$ loading into Lake Erie. In the St. Joseph River watershed, a tributary of the Maumee River, $48 \%$ of the total P and $49 \%$ of the soluble $\mathrm{P}$ losses from fields occurred through tile flow.

Gypsum is a good source of calcium (Ca) and sulfur (S) for plant nutrition and has several uses as a soil amendment including alleviating subsoil acidity, ameliorating 
excess soil sodium $(\mathrm{Na})$, and improving soil water drainage (Dick et al. 2008). Flue gas desulfurization gypsum is produced by coal-burning power plants when the flue gases are scrubbed with a limestone slurry to remove sulfur oxides. This gypsum also has the ability to reduce soluble reactive $\mathrm{P}$, the form that causes eutrophication, in agricultural runoff by precipitating some of the $\mathrm{P}$ without causing a strong effect on soil test $\mathrm{P}$ (i.e., the $\mathrm{P}$ that is available to crops) (Stout et al. 2003; Brauer et al. 2005). A recent report clearly established the potential of using gypsum as a soil amendment to mitigate or reduce soluble $\mathrm{P}$ runoff from agricultural soils (King et al. 2016). This article provides additional information from a larger number of field sites, but is restricted to only analyses of tile flow water samples.

\section{APPLICATION OF GYPSUM AS A SOIL AMENDMENT}

The effect of gypsum soil amendment on chemistry of tile drainage from agricultural fields in the Maumee Basin was monitored from May of 2012 through June of 2015 beginning with three farms in 2012, adding another five farms in 2013, and finally adding one farm in 2015. Paired fields that were hydrologically similar were selected with one field receiving gypsum at 2.24 $\mathrm{Mg} \mathrm{ha}{ }^{-1}\left(1 \mathrm{tn} \mathrm{ac}^{-1}\right)$ and the other serving as a control. If paired fields could not be located, a large field was split into three sections with one section receiving gypsum, a second section serving as control, and a third section serving as a buffer between the treated and untreated sections. Sections of a field were selected by mapping independent tile drain outlets so there was no mixing of water from the treated and untreated sections.

Grab water samples were collected from the paired areas during rainfall events and also between events, if possible. Samples were analyzed for soluble P. For these preliminary studies, flow rate instrumentation was not available, and so we can only report changes in concentrations and not loads. For a detailed study of the effects of gypsum on reducing both concentrations and loads from a field in Ohio with very high soil P values, see King et al. (2016).

\section{OBSERVATIONS RELATED TO EFFECT OF GYPSUM ON PHOSPHORUS CONCENTRATIONS IN TILE FLOW}

Soluble P concentrations $\left(\mathrm{mg} \mathrm{L}^{-1}\right)$ in tile water samples for all sites combined from May of 2012 through June of 2015 ranged from the detection limit of 0.01 to 0.51 $\mathrm{mg} \mathrm{L}^{-1}$, with an overall mean of $0.075 \mathrm{mg}$ $\mathrm{L}^{-1}$. Mean orthophosphate concentration was 0.055 from gypsum-treated fields and 0.086 from untreated fields. Mean concentration was lower on gypsum-treated versus untreated fields for six of nine sampled farms. For 89 sampling events, $P$ was lower on gypsum-treated fields for 58 events, was lower on untreated fields for 24 events, and was not affected by gypsum for 7 events. The critical value of soluble $\mathrm{PO}_{4}$ for supporting massive algal blooms is $0.015 \mathrm{mg}$ $\mathrm{L}^{-1}$. Orthophosphate concentrations in tile water were less than this critical value for 17 events on gypsum-treated fields and 14 events on untreated fields.

Soluble $\mathrm{P}$ reductions were calculated from 87 sample pairs. Positive percentage reduction indicates that concentration was lower on the gypsum treated field than the control, and negative percentage reduction indicates the concentration was higher on the gypsum treated field than the control. Positive reductions were observed for $65 \%$ of the samples, with a maximum reduction of $93 \%$.
Figure 2 shows a scatter plot of paired sample $\mathrm{P}$ reductions for 87 sampling events as a function of the soluble $\mathrm{P}$ concentrations measured on the control fields. The effect of concentration on $\mathrm{P}$ reduction is clearly evident. Below $0.1 \mathrm{mg} \mathrm{L}^{-1}$, the data are widely scattered, with reductions ranging from $-83 \%$ to $+85 \%$. This scatter likely reflects natural variability at low concentrations and analytical accuracy near the detection limit. At concentrations above $0.1 \mathrm{mg} \mathrm{L}^{-1}, 27$ of the 28 data pairs exhibited positive values, with reductions between $20 \%$ and $93 \%$. This result is significant in the fact that gypsum is most effective in reducing soluble $\mathrm{P}$ levels when they are at the high end of concentrations where their environmental impact is greatest.

Gypsum is considered a slightly soluble salt. This allows the gypsum to react rather quickly with soluble $\mathrm{P}$ and thus reduce the $\mathrm{P}$ concentrations. It also allows the $\mathrm{Ca}$ and $\mathrm{S}$ in the gypsum to move downward into the soil profile where it can help improve soil chemical, physical, and biological properties. Often these are the main reasons farmers apply gypsum to their fields. The disadvantage of this solubility is that the impact of the gypsum to control soluble $\mathrm{P}$ concentration will decrease with time as the gypsum is flushed from the surface or surface layer

\section{Figure 2}

Percentage reduction in soluble phosphorus $(P)$ concentrations on the gypsum-treated fields compared to soluble $\mathrm{P}$ concentrations in the control (i.e. untreated fields).

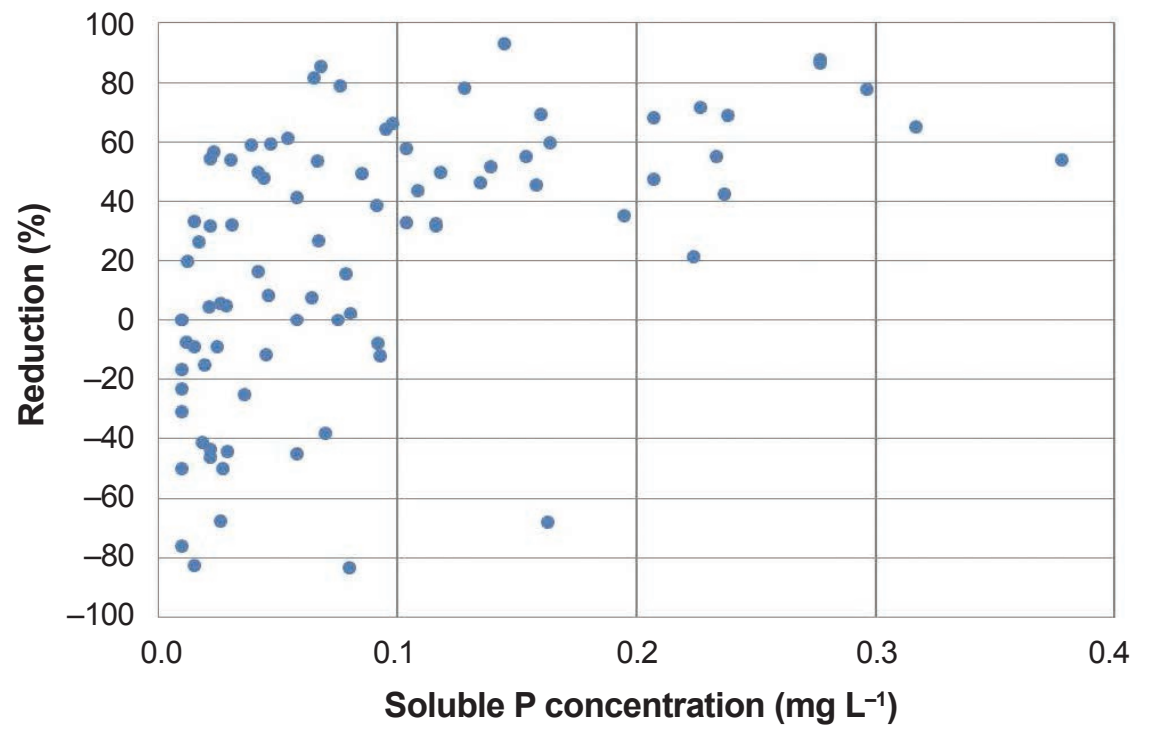


of soil where it is most effective in reducing soluble $\mathrm{P}$ concentrations.

To evaluate the change in gypsum effectiveness over time, reductions in $\mathrm{P}$ concentrations versus days after gypsum application are plotted in figure 3. Although scatter in the data is clearly observed, the regression coefficient of 0.02063 is at the $p<0.04$ level of significance. The best-fit equation of a line for these data in figure 3 is $y=43.85-0.02063 x$, where $y$ is the percentage reduction in $\mathrm{P}$ concentration and $x$ is the number of days since gypsum application. For each day after gypsum application, P concentrations affected by gypsum application are reduced by $0.021 \%$. Thus, after 100 days, the gypsum effect on $\mathrm{P}$ concentrations in tile drainage water is reduced by $2.1 \%$, and after 1,000 days the gypsum effect is reduced by $21 \%$. It is clear that the gypsum effect is still evident even three years after application, although the effectiveness is diminished and reapplication may be required.

The relationship between $\mathrm{P}$ concentration reductions and days since gypsum application (figure 3) would have been greatly improved if the data could have been grouped by flow rate categories, e.g., baseflow versus storm flow.

\section{CONCLUSIONS}

The results from the field studies reported here and the work reported by King et al. (2016) clearly indicate that the use of flue gas desulfurization gypsum for reducing $\mathrm{P}$ concentrations and loads from fields needs to be further studied and evaluated. At the least, since more and more farmers are applying gypsum as a soil amendment to improve their soils and crops, the additional water quality benefits need to be quantified. Additional studies could also lead to improved management strategies that would enhance the overall effect of gypsum on reducing $\mathrm{P}$ losses from soils as our preliminary data have shown that gypsum, at least in the first year or two after application, can achieve the $41 \%$ reduction in P losses from fields, and thus also possible P loadings into Lake Erie.

\section{ACKNOWLEDGEMENTS}

Appreciation is expressed for the excellent cooperation of our farmer collaborators. Support

\section{Figure 3}

Percentage reduction in soluble phosphorus $(P)$ concentrations as a function of days after gypsum application.

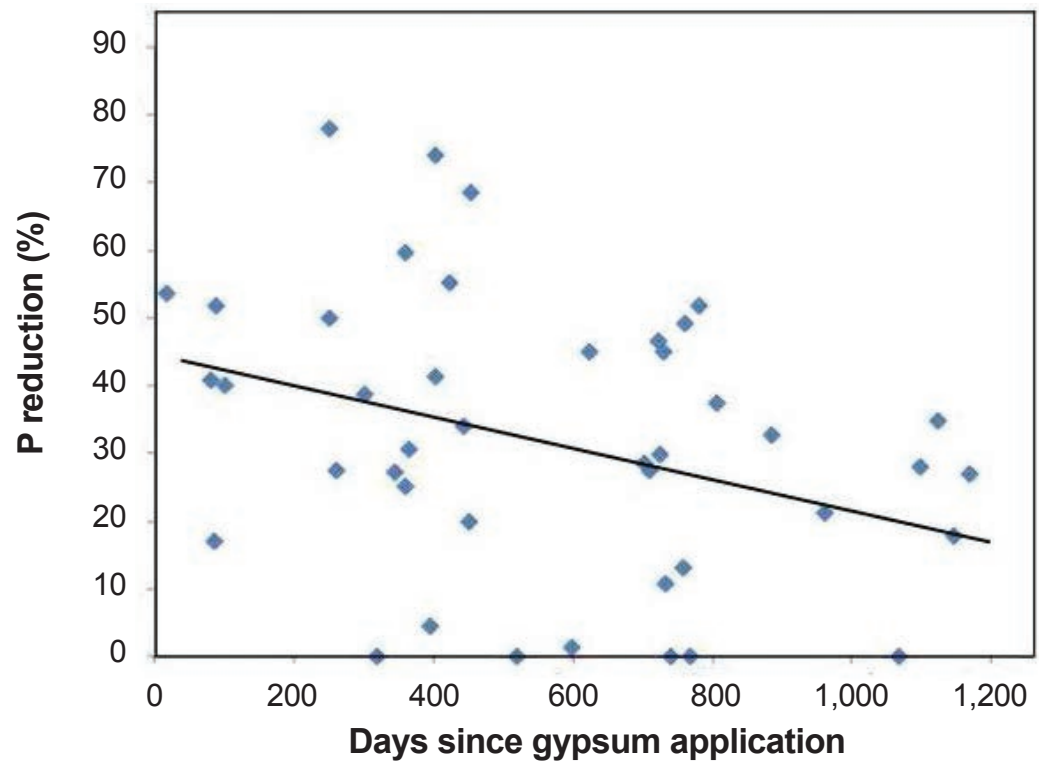

for this research was obtained from the USDA Natural Resources Conservation Service, the Ohio Department of Development (Columbus, Ohio), the Electric Power Research Institute (Palo Alto, California), and from state and federal funds appropriated to The Ohio State University and The Ohio Agricultural Research and Development Center.

\section{REFERENCES}

Brauer, D., G.E. Aiken, D.H. Pote, S.J. Livingston, L.D. Norton, T.R. Way, and J.H. Edwards. 2005. Amendment effects on soil test phosphorus. Journal of Environmental Quality 34:1682-1686.

Dick, W.A., D. Kost, and L. Chen, 2008. Availability of sulfur to crops from soil and other sources. In Sulfur: A Missing Link Between Soils, Crops, and Nutrition. Agronomy Monograph No. 50, ed. J. Jez, 59-82. Madison, WI: American Society of Agronomy, Crop Science Society of America, and Soil Science Society of America.

King, K.W., M.R. Williams, W.A. Dick, and G.A. LaBarge. 2016. Decreasing phosphorus loss in tile-drained landscapes using flue gas desulfurization gypsum. Journal of Environmental Quality 45:1722-1730

National Academy of Sciences. 1969. Eutrophication: causes, consequences, correctives. Washington, DC: National Academy of Sciences.

NOAA (National Oceanic and Atmospheric Administration). 2016. Experimental Lake Erie harmful bulletin, 1 November, 2016. https://
www.glerl.noaa.gov/res/HABs_and_Hypoxia/ lakeErieHABArchive/bulletin_2016-30.pdf.

Smith, D.R., K.W. King, and L. Johnson. 2015. Surface runoff and tile drainage transport of phosphorus in the Midwestern United States. Journal of Environmental Quality 44:495-502.

Stout, W.L., A.N. Sharpley, and S.R. Weaver. 2003. Effect of amending high phosphorus soils with flue gas desulfurization gypsum on plant uptake and soil fractions of phosphorus. Nutrient Cycling in Agroecosystems 67:21-29.

USGS (United States Geological Survey). 2012. Historic Earthquakes: New Madrid 1811-1812 Earthquakes. https://earthquake.usgs.gov/ earthquakes/events/1811-1812newmadrid/ summary.php.

Verduin, J. 1969. Man's influence on Lake Erie. Ohio Journal of Science 69:65-70. 